Article

\title{
The Influence of Selective Laser Melting Process Parameters on the Property of TiAlN/TiN Multilayer Coating on the 316L Steel
}

\author{
Yueling Lyu ${ }^{1,2, *}$, Jingwei Wang ${ }^{3}$, Yulin Wan ${ }^{3}$ and Yangzhi Chen ${ }^{3}$ \\ 1 School of Biomedical Engineering, Sun Yat-sen University, Guangzhou 510006, China \\ 2 State Key Laboratory of Tribology, Tsinghua University, Beijing 100084, China \\ 3 School of Mechanical and Automotive Engineering, South China University of Technology, \\ Guangzhou 510641, China; w245162265@163.com (J.W.); wan_yulin@163.com (Y.W.); \\ meyzchen@scut.edu.cn (Y.C.) \\ * Correspondence: lvyueling88@126.com; Tel.: +86-20-8711-4915
}

Received: 17 April 2019; Accepted: 4 June 2019; Published: 10 June 2019

\begin{abstract}
Selective laser melting (SLM) is an important advanced additive manufacturing technology. The existing SLM products cannot fully meet the requirements of high-precision and strength of the mechanical component because of their defects. The TiAlN/TiN multilayer coating can improve the surface property of SLM products. The present work aims to explore the influences of different process parameters of SLM on the property of TiAlN/TiN multilayer coating plating on the 361L specimen and the mechanism of these influences. Taking laser power, scanning speed, and scanning space as factors, an orthogonal experiment was designed. The TiAlN/TiN multilayer coating specimens can be obtained by plating on the $361 \mathrm{~L}$ specimen, fabricated by the process parameters of SLM on the orthogonal experiment. The surface topographies and properties of TiAlN/TiN multilayer coating were tested, the influences of SLM process parameters on TiAlN/TiN multilayer coating were analyzed, and the optimal process parameter was obtained. The electron microscope images revealed that the surface morphology of TiAlN/TiN multilayer coating plating on the SLM specimen was relatively flat, and there were some macro-particles in different sizes and pin holes dispersed on it. The thickness of the TiAlN/TiN multilayer coating was $2.77-3.29 \mu \mathrm{m}$. The microhardness value of coating SLM specimen was more than four times that of the uncoated SLM specimen and the wear rates of the uncoated specimen were 2-4 times that of the corresponding coating specimen. The comprehensive analysis shows that the laser power had the greatest influence on the comprehensive property of the coating. The primary cause of the influence of SLM process parameters on the properties of the TiAlN/TiN multilayer coating was preliminarily discussed. When the laser power was $170 \mathrm{~W}$, the scanning speed was $1,100 \mathrm{~mm} / \mathrm{s}$, and the scanning space was $0.08 \mathrm{~mm}$, the TiAlN/TiN multilayer coating plating on the SLM specimen had the best comprehensive property.
\end{abstract}

Keywords: selective laser melting (SLM); process parameters; TiAlN/TiN multilayer coating; multi-arc ion plating technique; mechanical property

\section{Introduction}

The surface of mechanical components should have good abrasion resistance, high strength, and other surface properties to extend their service lifetime. There are many methods to improve the surface property of a component such as plasma techniques, shoot penning, chemical vapor deposition and physical vapor deposition, and so on. The selective laser melting (SLM) is an advanced additive manufacturing technology, with the characteristics of a high degree of freedom in manufacturing, low cost, and high efficiency [1]. However, various defects are easy to occur in the SLM specimens, 
such as oxides, voids, cracks, residual stress, balling, and porosities [2]. Currently, there are many methods to improve the mechanical and surface properties of SLM specimens. The main way to improve the quality of SLM specimens are to change the process parameters of SLM, such as laser power, scanning strategy [3], scanning speed, scanning space [4], layer thickness [5], particle size of powder, materials, and so on. Thijs et al. [6] studied the influence of different scanning speeds with the alternating and the unidirectional scan vector on the microstructure of the Ti-6Al-4V alloy processed by SLM. Ortner et al. [7] found that residual stress could improve the fracture toughness of steel. A traditional heat treatment process is also a method of the surface strengthening treatment of SLM specimens. The SLM specimens can improve their surface appearance and mechanical properties to meet the needs of specific components by grinded, electro-blasted, mechanical-polished, residual stress relieving, surface peening treatment, plasma techniques, heat treatments, and Hot-Isotactic Pressing. Löber et al. [8] have studied different post processing techniques, such as simple grinding, electro and plasma polishing, and blasting with different grits, to improve the high-surface roughness (SR) characteristic of parts generated by SLM. Kamariah et al. [9] studied the effect of heat treatments on the micro-hardness of 316L stainless steel parts. The physical vapor deposition technology, especially the multi-arc ion plating technology, has been less studied as a post-treatment method to improve the property of SLM specimens.

In recent years, TiAlN coating, fabricated by multi-arc ion plating technology because of its advantages of high hardness, high oxidation temperature, good thermal hardness, strong adhesion, low friction coefficient, and low thermal conductivity, is widely applied to improve the surface properties [10]. Now, the development of TiAlN/TiN coating technology has changed from single-layer and single-component film to multilayer, gradient multi-component composite, and multi-function, which can improve subtract-coat adherence. Wei et al. studied the TiAlN/TiN multilayer coatings with different modulation ratio. Their results indicated that the modulation ratio effects the microstructure and properties of TiAlN/TiN multilayer coatings, which optimal process parameters would be quite favorable for industrial application in the future [11]. S. PalDey and S.C. Deevi reviewed the single layer and multilayer wear-resistant coatings of TiAlN obtained by various physical vapor deposition (PVD) techniques [12]. The TiAlN/TiN multilayer coatings were deposited on M2 high-speed steel (HSS) by arc ion plating with separate targets to decrease the unfavorable macroparticles [13]. Yongqiang Wei and Chunzhi Gong studied the effect of pulsed bias duty ratio on the microstructure, mechanical, and wear properties of TiAlN/TiN multilayer coatings deposited on M2 high-speed steel by a pulsed bias arc ion plating system [14].

The mechanical components manufactured by the existing SLM technology cannot totally meet the requirements of high precision and strength because of their defects. The surface mechanical properties of SLM specimens can be improved by using a TiAlN/TiN multilayer coating fabricated by multi-arc ion plating on the surface of SLM specimens. While different substrates have certain effects on the properties of the TiAlN/TiN multilayer coating [15], the main factors affecting the property of TiAlN/TiN multilayer coating include the hardness of substrate, the surface morphology of substrate, coating process parameters, etc. Many studies have focused on the influence of coating process parameters on TiAlN coating. As mention before, SLM process parameters have an important influence on properties (especially hardness, roughness, surface morphology, porosity, etc.) of SLM specimens. That means, SLM process parameters will also affect the property of TiAlN/TiN multilayer coating deposited on SLM substrate. However, no scholars have studied how these process parameters affect the property and the mechanism of the impact. Therefore, the present work aims to explore the influence of different process parameters of SLM on the property of TiAlN/TiN multilayer coating plating on the SLM specimen and the mechanism of these influences. Taking laser power, scanning speed, and scanning space as factors, an orthogonal experiment was designed. The TiAlN/TiN multilayer coating plating on the SLM specimen fabricated by the process parameters on the orthogonal experiment can be obtained. The surface topography and property of substrates and TiAlN/TiN multilayer coatings were tested, the influences of SLM process parameters on TiAlN/TiN multilayer 
coating were analyzed, and the optimal process parameter was obtained. This study will provide another form of surface post-treatment for SLM samples. The optimal process parameter obtained can be used to manufacture the SLM specimen for TiAlN/TiN multilayer coating. The coatings can cover cracks and pin holes of the SLM 361L specimen and can prove hardness of the SLM 361L specimen and antifriction wear-resisting. The coated SLM sample can be applied to functional elements such as micro gear, robot joint, and aerospace.

\section{Materials and Methods}

\subsection{Specimens Made by Selective Laser Melting (SLM)}

The SLM processing for the substrate specimens was carried out using a Dimetal-280 selection laser melting machine (South China University of Technology, China) [6]. The material used for the SLM processing was a gas-atomized stainless steel 316L powder with maximum particle diameter of $45 \mu \mathrm{m}$ and minimum particle diameter of $15 \mu \mathrm{m}$.

The size of the substrate specimens was a cuboid of $25 \mathrm{~mm} \times 16 \mathrm{~mm} \times 3 \mathrm{~mm}$, with through hole $\varphi 4 \mathrm{~mm}$.

For studying the process parameters, the orthogonal experiment was designed, which is shown in Table 1 . The laser power was $170-210 \mathrm{~W}$, the scanning-speed was $1000-1200 \mathrm{~mm} / \mathrm{s}$, and the scanning space was $0.04-0.08 \mathrm{~mm}$.

Preparation involved virtually slicing the three-dimensional (3D) substrate specimen, in the form of a CAD file, into a sequence of two-dimensional (2D) slices. The $25 \mathrm{~mm} \times 3 \mathrm{~mm}$ plane was the two-dimensional slices plane. The scanning layers were $30 \mu \mathrm{m}$.

Table 1. L9 $\left(3^{3}\right)$ orthogonal test table.

\begin{tabular}{cccc}
\hline Number & Power & Scanning Speed & Scanning Space \\
\hline 1 & $170 \mathrm{~W}$ & $1000 \mathrm{~mm} / \mathrm{s}$ & $0.04 \mathrm{~mm}$ \\
2 & $170 \mathrm{~W}$ & $1100 \mathrm{~mm} / \mathrm{s}$ & $0.06 \mathrm{~mm}$ \\
3 & $170 \mathrm{~W}$ & $1200 \mathrm{~mm} / \mathrm{s}$ & $0.08 \mathrm{~mm}$ \\
4 & $190 \mathrm{~W}$ & $1000 \mathrm{~mm} / \mathrm{s}$ & $0.06 \mathrm{~mm}$ \\
5 & $190 \mathrm{~W}$ & $1100 \mathrm{~mm} / \mathrm{s}$ & $0.08 \mathrm{~mm}$ \\
6 & $190 \mathrm{~W}$ & $1200 \mathrm{~mm} / \mathrm{s}$ & $0.04 \mathrm{~mm}$ \\
7 & $210 \mathrm{~W}$ & $1000 \mathrm{~mm} / \mathrm{s}$ & $0.08 \mathrm{~mm}$ \\
8 & $210 \mathrm{~W}$ & $1100 \mathrm{~mm} / \mathrm{s}$ & $0.04 \mathrm{~mm}$ \\
9 & $210 \mathrm{~W}$ & $1200 \mathrm{~mm} / \mathrm{s}$ & $0.06 \mathrm{~mm}$ \\
\hline
\end{tabular}

\subsection{Pretreatment and Coating on Specimens}

The specimens were grounded with a series of SiC papers of 100 grit, 800-2000 grit, and finally polished, degreased, and ultrasonically cleaned [16]. In order to remove the oil and other impurities on the surface and keep the specimen surface smooth and clean, all specimens were ultrasonically cleaned with acetone and ethanol in an ultrasonic bath for $20 \mathrm{~min}$ respectively, blow-dried, and stored in a desiccator prior to the coating operation.

All coatings were deposited using PVD/PECVD-600 multi-arc ion plating equipment. The specimens were placed on a rotary specimen holder, which kept the rotation speed of $8 \mathrm{rpm}$ during the deposition. The cathodes were TiAl (50:50 at.\%) alloy and pure Ti (99.9\%), from which titanium and aluminum plasmas were generated. The reactive gas with high-pure (99.999\%) nitrogen was introduced into the deposition chamber to form TiN and TiAlN layers. After the chamber was evacuated below $1 \times 10^{-3} \mathrm{~Pa}$, high-pure (99.999\%) Ar gas was introduced into the chamber to sputter the surface of substrates in order to clean and remove contaminants. After $15 \mathrm{~min}$, Ti interlayer evaporated with an arc current of $60 \mathrm{~A}$ was deposited for $5 \mathrm{~min}$ to improve the adhesion of coatings to the substrate. A substrate temperature was $25^{\circ} \mathrm{C}$ at the beginning of the deposition. Then $\mathrm{N}_{2}$ gas was added as a reactive gas to deposit the TiN monolayer as the transition layer for $5 \mathrm{~min}$. The working 
pressure was $0.48 \pm 0.02 \mathrm{~Pa}$. Subsequently, TiAl targets were evaporated with an arc current of $60 \mathrm{~A}$ to deposit the TiAlN monolayer for $90 \mathrm{~min}$. During the deposition, a pulsed power source was used to generate a negative pulsed bias on the specimens, pulsed bias voltage was $U_{\mathrm{p}}=400 \mathrm{~V}$, pulsed frequency was $f=40 \mathrm{kHz}$, the duty ratio was $20 \%$, and the substrate temperature during deposition of TiAlN/TiN coatings was $98^{\circ} \mathrm{C}$.

\subsection{Testing Method of Specimens}

The surface morphologies of the TiAlN/TiN multilayer coatings were obtained by environmental scanning electron microscope (ESEM) (Quanta 200, Holland FEI, Eindhoven, The Netherlands).

Microhardness tests were also carried out in Shimadzu Vickers microhardness HMV-2T tester (Kyoto, Japan) with a load of $25 \mathrm{mgf}$ and a hold time of $10 \mathrm{~s}$. In order to ensure the accuracy and repeatability of microhardness, five measurements were done on each specimen.

The thicknesses of coatings were measured by scanning electron microscope of Nova NanoSEM 430 (Holland FEI, Eindhoven, The Netherlands).

The adhesions of the TiAlN/TiN multilayer coating were investigated with an automatic scratch-tester at UMT-2 equipped. The normal force of the indenter onto the specimen surface was increased continuously from 0 to $80 \mathrm{~N}$, with the loading speed of $80 \mathrm{~N} / \mathrm{min}$ and a track length of $5 \mathrm{~mm}$. The chemical compositions of the scratch were determined from environmental scanning electron microscope (ESEM) (Quanta 200). Because the TiAlN/TiN multilayer coating contains no Fe element, while the 316L steel substrate contains a large amount of $\mathrm{Fe}$, the adhesion can be determined by the change of Fe element content in the scratch. When the coating is scratched out, the Fe content will increase suddenly, and this position is the abrupt position of Fe content. The distance between the abrupt position of Fe content and the starting point of the scratch is $x$, it is also the point that the coating began to emerge as angular cracking. The adhesion can be calculated by the ratio of $x$ to the total length of the scratch, $\mathrm{s}$, times the maximum loading. The adhesion $L_{\mathrm{c}}$ [17] can be calculated according to Equation (1), where $F_{\text {nmax }}$ is the maximum normal load for the scratch test, $F_{\text {nmax }}=80 \mathrm{~N}$, $s$ is the total length of the scratch, and $s=5 \mathrm{~mm}$.

$$
L_{\mathrm{c}}=F_{\mathrm{nmax}} \times x / \mathrm{s}
$$

The wear tests were carried out on the reciprocating friction and wear test-rig of UMT-TriboLab (Bruker, San Jose, CA, USA). $\mathrm{Si}_{3} \mathrm{~N}_{4}$ balls with a diameter of $9 \mathrm{~mm}$ were used as the mating components. The same load of $10 \mathrm{~N}$, sliding speed of $5 \mathrm{~mm} / \mathrm{s}$, and the sliding distance of $10 \mathrm{~mm}$ were applied to all of the tests. The tests lasted for $20 \mathrm{~min}$ at ambient temperature and humidity. After the wear tests, a 3D optical profiler (Taylor Hobson, Leicester, UK) was used to measure the depth profiles of the wear tracks.

\section{Results}

\subsection{Surface Topography Analysis}

Figure 1 shows the surface morphologies of number (No.) 1 and 9 substrate specimens after polished. The surface morphologies of other substrate specimens are not listed here. From Figure 1, it can be obtained that there are some voids, high-density dimples, and even cracks in the surface of the substrate, even though the substrate is polished. Different SLM process parameters result in different hole and crack conditions [1]. The cracks, voids, and dimples exist in the No. 1 substrate specimen while only some voids and dimples exist in the No. 9 substrate specimen. Figure 2 shows the surface morphology of coating specimens. From Figure 3, it can be obtained that there are macro-particles in different sizes and pin holes dispersed on the surface of the TiAlN/TiN multilayer coating [18]. The arc discharge on the target surface produced metallic macro-particles which were splattered onto the coating surface during deposition. The spalling of macro-particles by re-sputtering, and/or collision, thus, a few pin holes were left on the surface of the coating. The size of the macro-particles was less 
than $10 \mu \mathrm{m}$. In Figure 2, there was not much difference in the surface morphology of each specimen, but there were relatively more and larger particles in Figure $2 \mathrm{~d}-\mathrm{f}$.
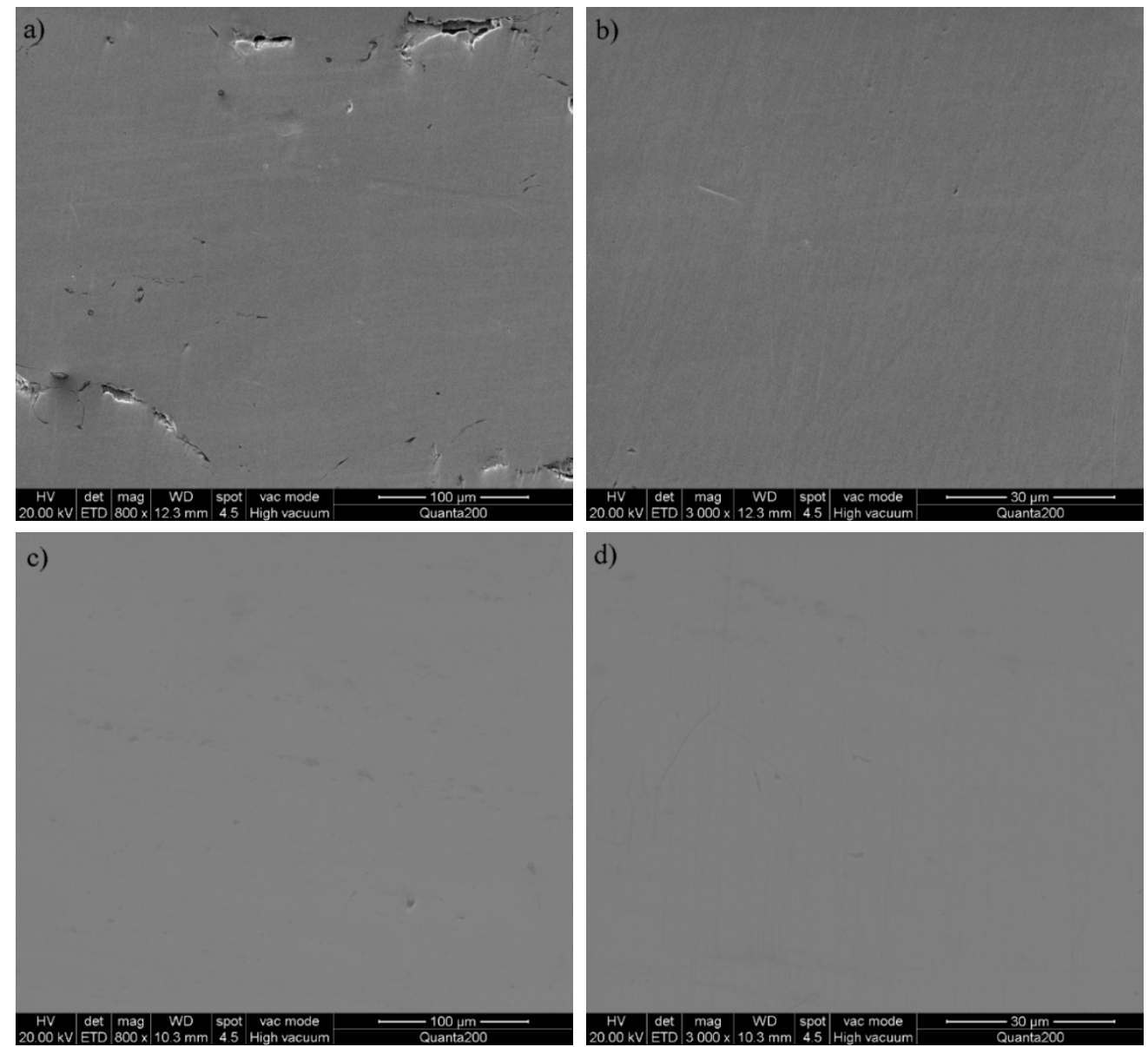

Figure 1. Surface morphologies of substrate specimens: (a) No. 1 at 800 magnification, (b) No. 1 at 3000 magnification, (c) No. 9 at 800 magnification, (d) No. 9 at 3000 magnification.
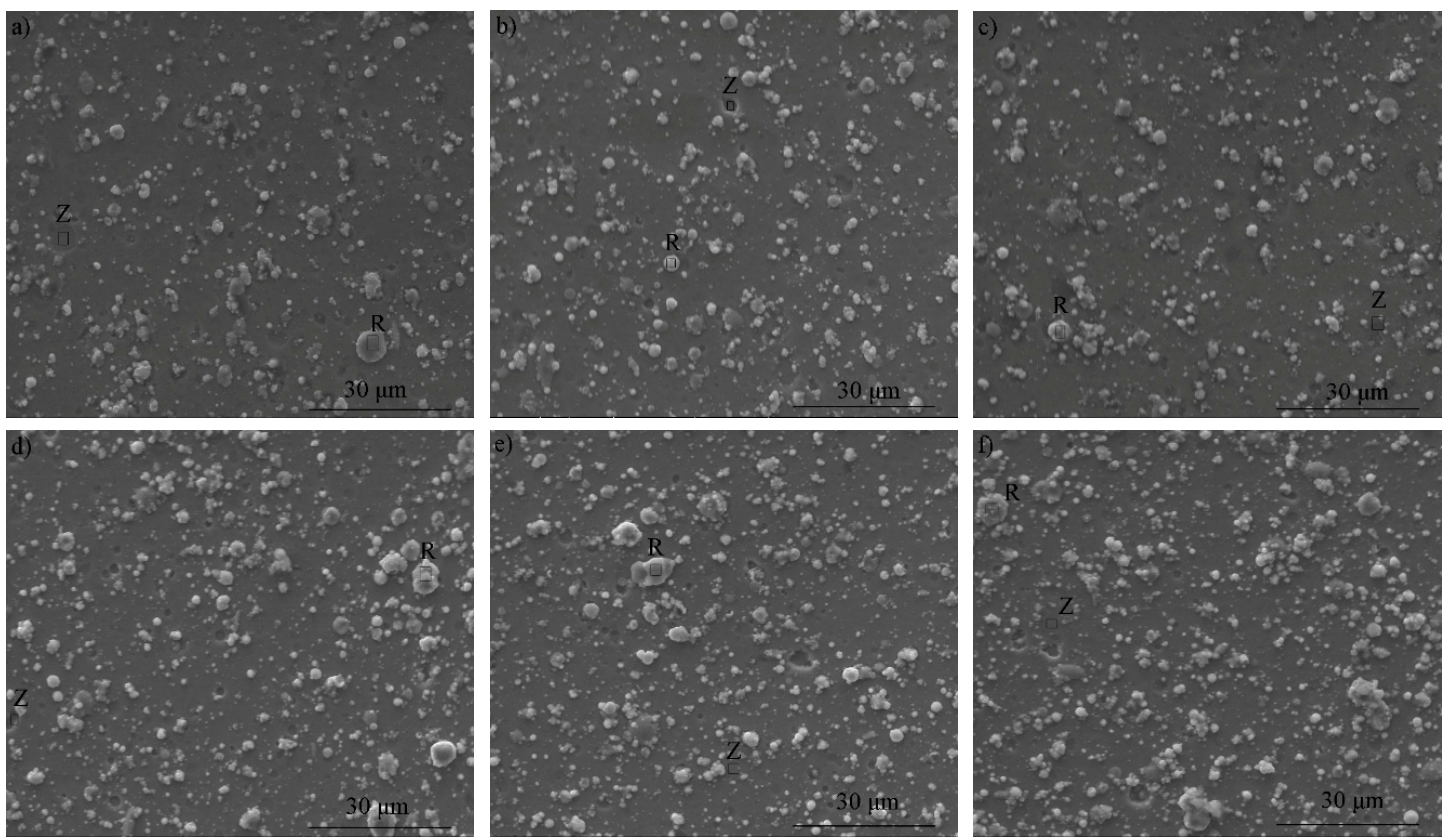

Figure 2. Cont. 

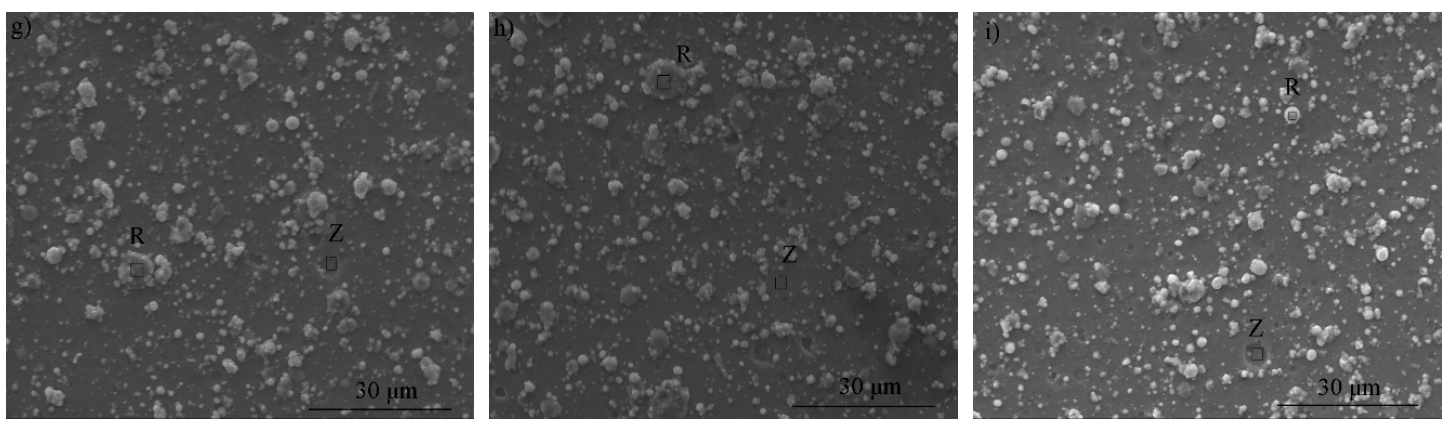

Figure 2. Surface scanning electron microscope (SEM) micrographs of Nos. 1-9 coating specimens: (a) No. 1 coating specimen; (b) No. 2 coating specimen; (c) No. 3 coating specimen; (d) No. 4 coating specimen; (e) No. 5 coating specimen; (f) No. 6 coating specimen; (g) No. 7 coating specimen; (h) No. 8 coating specimen; (i) No. 9 coating specimen.

By energy dispersive X-ray spectroscopy (EDS), the element compositions of macro-particles and pin holes were obtained and are displayed in Table 2. Table 2 shows that the element compositions of macro-particles and pin holes of the coatings are not different, although the percentage of elements is different. The main elements of macro-particles are $\mathrm{N}, \mathrm{Ti}$, and $\mathrm{Al}$, which is similar to the composition of the target materials. The macro-particles on the surface were indeed formed by the deposition of droplets splattering from cathode materials. The small amount of $\mathrm{Fe}$ and $\mathrm{Cr}$ detected in Table 2 should be the one in the $316 \mathrm{~L}$ steel substrate.

Table 2. Compositions of typical regions of coating specimens on energy dispersive X-ray spectroscopy (EDS) spectrums.

\begin{tabular}{|c|c|c|c|c|c|c|}
\hline \multirow{2}{*}{\multicolumn{2}{|c|}{ Compositions }} & $\mathbf{N}$ & Al & $\mathrm{Ti}$ & $\mathrm{Fe}$ & $\mathrm{Cr}$ \\
\hline & & \multicolumn{5}{|c|}{ Weight Percentage (\%) } \\
\hline \multirow[b]{2}{*}{1} & Z & 15.17 & 13.35 & 71.48 & - & - \\
\hline & $\mathrm{R}$ & 20.09 & 23.33 & 56.03 & 0.56 & - \\
\hline \multirow{2}{*}{2} & Z & 30.19 & 17.84 & 51.50 & 0.47 & - \\
\hline & $\mathrm{R}$ & 13.69 & 17.10 & 65.22 & 3.20 & 0.79 \\
\hline \multirow{2}{*}{3} & $\mathrm{Z}$ & 18.38 & 18.53 & 62.56 & 0.53 & - \\
\hline & $\mathrm{R}$ & 10.80 & 22.56 & 65.97 & 0.67 & - \\
\hline \multirow{2}{*}{4} & Z & 30.65 & 15.66 & 53.35 & 0.34 & - \\
\hline & $\mathrm{R}$ & 20.42 & 17.35 & 61.51 & 0.72 & - \\
\hline \multirow{2}{*}{5} & Z & 10.45 & 7.45 & 81.17 & 0.65 & 0.28 \\
\hline & $\mathrm{R}$ & 29.05 & 17.35 & 52.99 & 0.61 & - \\
\hline \multirow{2}{*}{6} & Z & 28.49 & 15.45 & 55.71 & 0.35 & - \\
\hline & $\mathrm{R}$ & 29.19 & 14.48 & 55.81 & 0.51 & - \\
\hline \multirow{2}{*}{7} & Z & 30.13 & 15.80 & 54.07 & - & - \\
\hline & $\mathrm{R}$ & 29.81 & 17.07 & 53.13 & - & - \\
\hline \multirow{2}{*}{8} & Z & 24.16 & 14.15 & 61.08 & 0.61 & - \\
\hline & $\mathrm{R}$ & 28.01 & 17.73 & 53.81 & 0.45 & - \\
\hline \multirow{2}{*}{9} & Z & 32.28 & 15.64 & 51.50 & 0.58 & - \\
\hline & $\mathrm{R}$ & 27.03 & 17.98 & 54.36 & 0.64 & - \\
\hline
\end{tabular}

\subsection{Microhardness}

The values of microhardness of the substrates and the coating specimens are shown in Table 3. According to Table 3, the microhardness of coating specimens is more than four times that of uncoated specimens. It can be said that TiAlN/TiN multilayer coatings have a significant effect on improving the microhardness of substrate specimens. As can be seen from Table 3, the microhardness of Nos. 1-9 
substrate specimens are stable, with small ranges of variation and standard deviation, while the corresponding specimen after coating has a large range of variation and standard deviation. Due to the thickness difference between different specimens and a large range of standard deviation, it is difficult to directly compare the microhardness between these coatings. Form the errors of microhardness values of the uncoating specimens and coating specimens, it can be obtained that the microhardness of coating specimens varies greatly in different positions, while the microhardness of uncoated samples is relatively stable at different positions.

Table 3. Microhardness value of specimens.

\begin{tabular}{ccc}
\hline No. & Coating Specimens (HV) & Uncoated Specimens (HV) \\
\hline 1 & $1285 \pm 147$ & $303 \pm 10$ \\
2 & $1296 \pm 131$ & $283 \pm 11$ \\
3 & $1415 \pm 224$ & $276 \pm 9$ \\
4 & $1127 \pm 43$ & $257 \pm 10$ \\
5 & $1164 \pm 116$ & $268 \pm 6$ \\
6 & $1231 \pm 88$ & $266 \pm 6$ \\
7 & $1225 \pm 131$ & $271 \pm 10$ \\
8 & $1242 \pm 66$ & $266 \pm 8$ \\
9 & $1281 \pm 144$ & $269 \pm 7$ \\
\hline
\end{tabular}

\subsection{Adhesion}

The scratch morphology and the Fe elemental content diagram of the TiAlN/TiN multilayer coating formed is presented in Figure 3. As described in Section 2, the length $x$ from the coating scratched out position to the scratch starting point has been marked in Figure 3. According to Equation (1), the adhesions of the TiAlN/TiN multilayer coating can be obtained in Table 4.

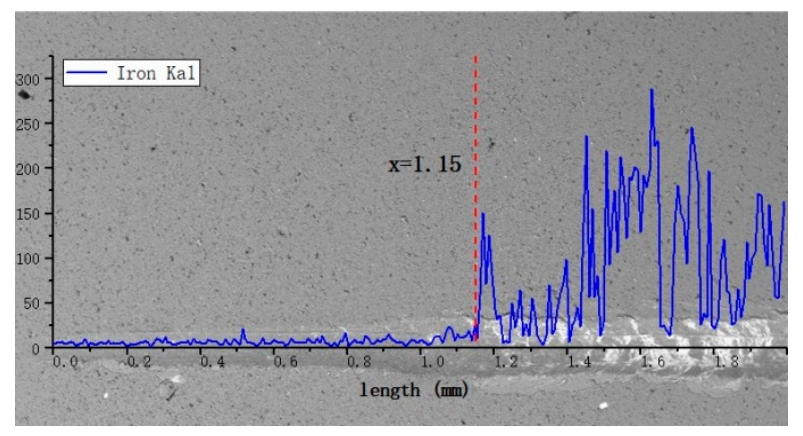

Figure 3. Scratch morphology and Fe elemental content diagram of the TiAlN/TiN multilayer coating.

Table 4. Adhesion of the TiAlN/TiN multilayer coating.

\begin{tabular}{cc}
\hline No. & $\boldsymbol{L}_{\mathbf{c}} \mathbf{( N )}$ \\
\hline 1 & 13.12 \\
2 & 16.32 \\
3 & 14.56 \\
4 & 23.36 \\
5 & 18.4 \\
6 & 21.44 \\
7 & 16.32 \\
8 & 27.52 \\
9 & 26.08 \\
\hline
\end{tabular}

From Table 4, the highest adhesion of the specimens is the No. 8 coating specimen, the adhesions of Nos. 1-3 coating specimens are relatively poor, and the adhesions of Nos. $4-9$ coating specimens 
fluctuate greatly. Taking the adhesion of the coating as the target result, the value of the range analysis of the orthogonal experiment is shown in Table 5. It can be seen from Table 5 that laser power is the main factor influencing coating adhesion, followed by scanning space, and finally, scanning speed. Moreover, the optimal combination of the orthogonal experiment is A3B2C2, that is, when the laser power is $210 \mathrm{~W}$, the scanning speed is $1100 \mathrm{~mm} / \mathrm{s}$, and the scanning space is $0.06 \mathrm{~mm}$, the adhesion of the coating obtained is optimal. The optimal option was not tested in the orthogonal experiment, while the adhesions of the Nos. 8 and 9 coating specimens with process parameters closed to the optimal scheme are also very high, which can indicate the accuracy of the range analysis.

Table 5. The range analysis of the orthogonal experiment of adhesion as the target result.

\begin{tabular}{ccccc}
\hline \multirow{2}{*}{ Factor } & \multicolumn{3}{c}{ Sum of Results of One Level } & \\
\cline { 2 - 4 } & $\mathbf{K 1 j}$ & $\mathbf{K} \mathbf{2} \mathbf{j}$ & $\mathbf{K} \mathbf{j}$ & \\
\hline Factor A & 44 & 63.2 & 69.92 & 25.92 \\
Factor B & 52.8 & 62.24 & 62.08 & 9.44 \\
Factor C & 62.08 & 65.76 & 49.28 & 16.48 \\
\hline
\end{tabular}

Notes: K1j: The sum of results of first level for corresponding factor; K2j: The sum of results of second level for corresponding factor; K3j: The sum of results of third level for corresponding factor; Factor A: Power; Factor B: Scanning speed; Factor C: Scanning space.

\subsection{Thickness}

The cross-sectional SEM images of Nos. 4, 5, and 7 coating specimens are show in Figure 4. Two layers of coating can be seen clearly corresponding to the TiN and TiAlN coatings in Figure 4. The Nos. 4 and 5 coating specimens were tightly bonded to the substrate, and no cracks were observed in the interface between the coating and the substrate. However, the cracks and voids exist in the interface between the coating and the substrate with the No. 7 coating specimen because its substrate had existing defects. The thickness of the No. 7 coating specimen was less than that of the Nos. 4 and 5 coating specimens, which is affected by the defects of the substrate.
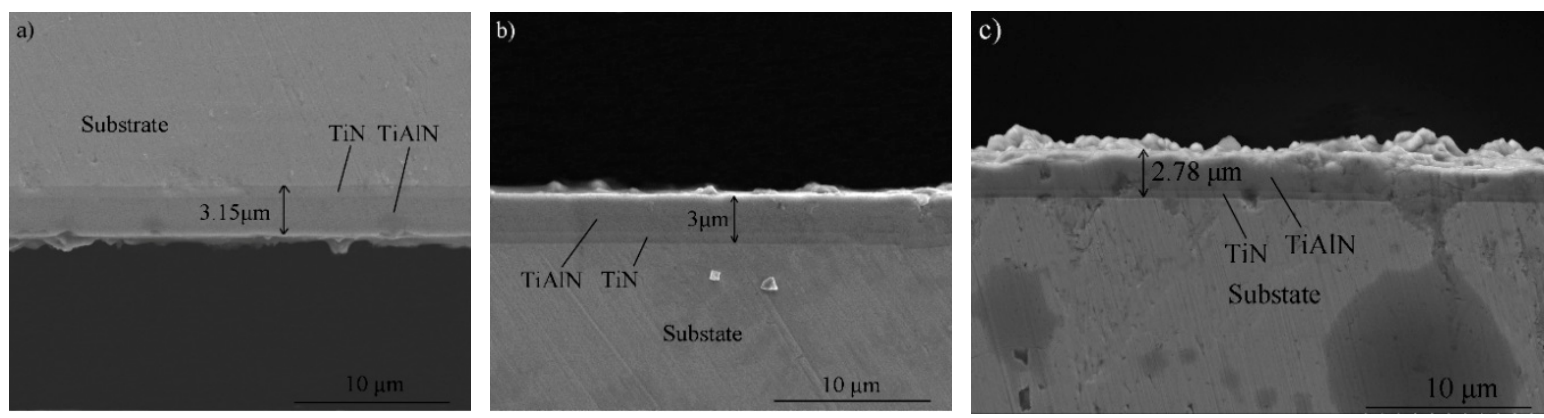

Figure 4. Cross-sectional SEM images of coating specimens: (a) No. 4, (b) No. 5, (c) No. 9.

The thicknesses of all coatings are show in Table 6. The coatings have the thickness of 2.77-3.29 $\mu \mathrm{m}$. From Table 6, the highest thickness of the specimens is the No. 8 specimen, the thicknesses of the Nos. 1-3 specimens are relatively poor, and the thicknesses of the Nos. 4-9 coating specimens fluctuate greatly, which is consistent with the rules of adhesions. From Tables 4 and 6, it can be seen that the adhesion increases with increasing coating thickness. Taking the thickness of the coating as the target result, the value of the range analysis of the orthogonal experiment is shown in Table 7 . It can be seen from Table 8 that laser power was the main factor influencing coating thickness, followed by scanning space, and finally, scanning speed. Moreover, the optimal combination of the orthogonal experiment was A3B2C2, that is, when the laser power was $210 \mathrm{~W}$, the scanning speed was $1100 \mathrm{~mm} / \mathrm{s}$, and the scanning space was $0.06 \mathrm{~mm}$, the thickness of the coating obtained was optimal. The optimal option was not tested in the orthogonal experiment, while the thicknesses of the Nos. 8 and 9 coating 
specimens with process parameters closed to the optimal scheme are also very high, which can indicate the accuracy of the range analysis.

Table 6. The thicknesses of the coatings.

\begin{tabular}{cc}
\hline No. & Value $(\mu \mathrm{m})$ \\
\hline 1 & 2.77 \\
2 & 2.91 \\
3 & 2.78 \\
4 & 3.15 \\
5 & 3 \\
6 & 3.06 \\
7 & 2.78 \\
8 & 3.29 \\
9 & 3.16 \\
\hline
\end{tabular}

Table 7. Range analysis of orthogonal experiment of thickness as the target result.

\begin{tabular}{ccccc}
\hline \multirow{2}{*}{ Factor } & \multicolumn{3}{c}{ Sum of Results of One Level } & \\
\cline { 2 - 4 } & $\mathbf{K} \mathbf{j}$ & $\mathbf{K} \mathbf{j}$ & $\mathbf{K} \mathbf{j}$ & Range \\
\hline Factor A & 8.46 & 9.21 & 9.23 & 0.77 \\
Factor B & 8.7 & 9.2 & 9 & 0.5 \\
Factor C & 9.12 & 9.22 & 8.56 & 0.66 \\
\hline
\end{tabular}

Notes: The sum of results of first level for corresponding factor; K2j: The sum of results of second level for corresponding factor; K3j: The sum of results of third level for corresponding factor; Factor A: Power; Factor B: Scanning speed; Factor C: Scanning space.

\subsection{Wear Property}

Figure 5 shows the morphologies of the worn surface for No. 1 uncoated and coating specimens. The morphologies of the worn surface of other specimens are not listed because the features of morphologies of other specimens are the same as that of No. 1 specimens. From Figure 5, the widths of the wear track of specimens were obviously inconsistent and the widths of the wear track of the uncoated specimens were wider, because the uncoated specimens were relatively soft. The uncoated specimens had obvious massive peeling layers and elongated traces of abrasive furrow action and even some cracks, indicating that the main form of wear were abrasive wear and adhesive wear. Compared with the wear track of the uncoated specimens, the wear tracks of the coating specimens were rough, the abrasive particles were distributed on both sides of the wear track, and there were obvious long and thin traces of abrasive furrow action in the middle of the wear tracks. A certain spalling phenomenon were existing coating specimens even though there were relatively few compared with the uncoated specimens. The abrasive wear and adhesive wear were also the main form of wear for the coating specimens. It was indicated that the coating had a good anti-wear effect on the substrate.

The selected areas of wear tracks were conducted by EDS, and the compositions are shown in Table 8. The analysis results by the EDS performed show some presence of the element from the $\mathrm{Si}_{3} \mathrm{~N}_{4}$ ball, indicating that the adhesive wear occurred as in the analysis above. In addition, the presence of the $\mathrm{O}$ element indicates that an oxidation reaction occurred during the wear test and $\mathrm{Al}_{2} \mathrm{O}_{3}$ or other oxides might be produced, which is consistent with the oxide layer observed in the cross-sectional SEM images. The analysis results of the coating specimens show the existence of the element from the TiAlN/TiN multilayer coating $(\mathrm{Ti}, \mathrm{Al})$ and the presence of the element from the substrate alloy $(\mathrm{Fe}, \mathrm{Ni}$, $\mathrm{Cr}, \mathrm{Mo}$ ), because the TiAlN/TiN multilayer coating was worn though in the wear test. The detected Ti and $\mathrm{Al}$ most likely originated from the debris of the broken TiAlN/TiN multilayer coating, which had not been brought away to the rim of the track by the relative motion of its counterpart during the test and was left on the worn surface. 

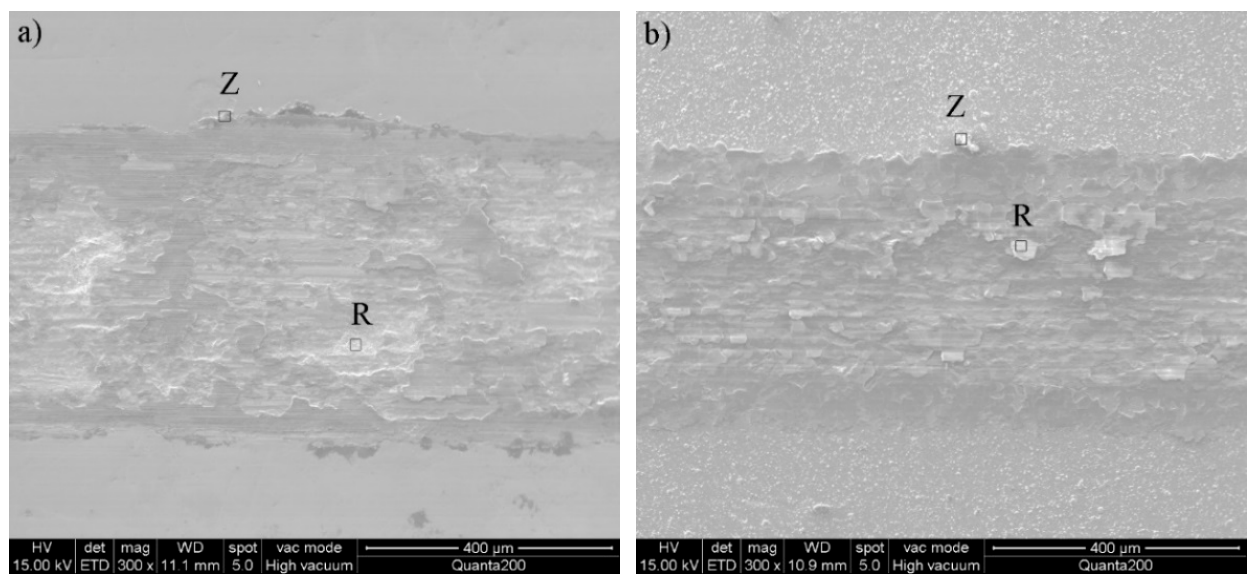

Figure 5. SEM morphologies of the worn surfaces of No. 1 specimens: (a) uncoated, (b) coating.

Table 8. Compositions of typical regions of the worn surfaces of No. 1 coating and uncoated specimens on EDS.

\begin{tabular}{|c|c|c|c|c|c|c|c|c|c|c|c|c|}
\hline \multirow{2}{*}{\multicolumn{3}{|c|}{ Compositions }} & $\mathbf{N}$ & Al & $\mathrm{Ti}$ & $\mathbf{F e}$ & $\mathrm{Cr}$ & $\mathrm{C}$ & $\mathbf{O}$ & Si & Mn & $\mathbf{N i}$ \\
\hline & & & \multicolumn{10}{|c|}{ Weight Percentage (\%) } \\
\hline \multirow{4}{*}{1} & \multirow{2}{*}{ Uncoated } & Z & - & - & - & 40.96 & 11.78 & 27.94 & 11.04 & 1.02 & - & 7.26 \\
\hline & & $\mathrm{R}$ & - & - & - & 51.77 & 14.41 & 5.4 & 17.14 & 1.04 & 0.89 & 9.34 \\
\hline & \multirow{2}{*}{ Coating } & $\mathrm{Z}$ & - & 9.05 & 23.08 & 3.75 & - & 32.11 & 32.01 & - & - & - \\
\hline & & $\mathrm{R}$ & - & 4.78 & 11.31 & 22.15 & - & 3.87 & 57.89 & - & - & - \\
\hline
\end{tabular}

The significant difference on profiles of wear track for the specimens can be seen in Figure 6. Compared with the uncoated specimens, the widths of the wear tracks of the coating specimens are narrower and the depths are shallower. Visually, it means that the wears of coating specimens are much less than that of uncoated specimens. In addition, both sides of the wear track of the coating specimens were steep, perhaps because during the wear test, the coating was worn out, and the microhardness of the substrate exposed at the bottom of the wear track was too low to anti-wear, compared to the coatings on both sides of the area. The wear tracks of the uncoated specimens with different process parameters were different, but both were wide and deep. The deepest values of all of wear tracks of the coating specimens exceeded $3 \mu \mathrm{m}$, which also indicated that the coating had been worn through, and that was consistent with the results of the EDS analysis.

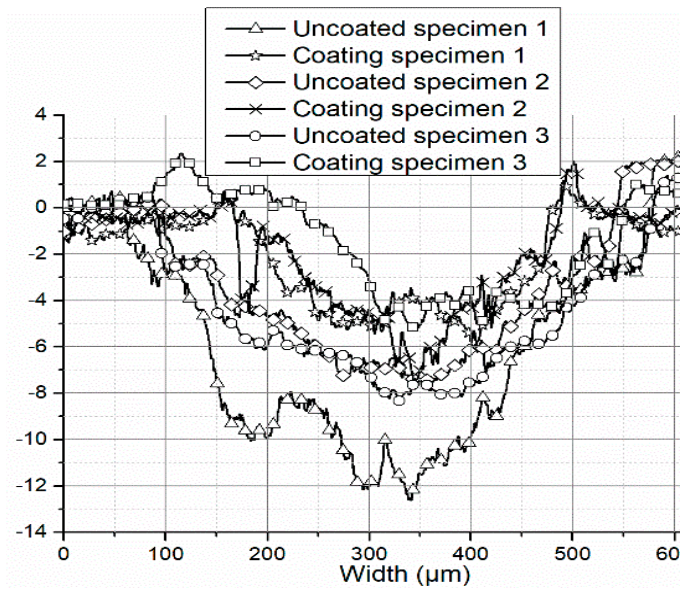

(a)

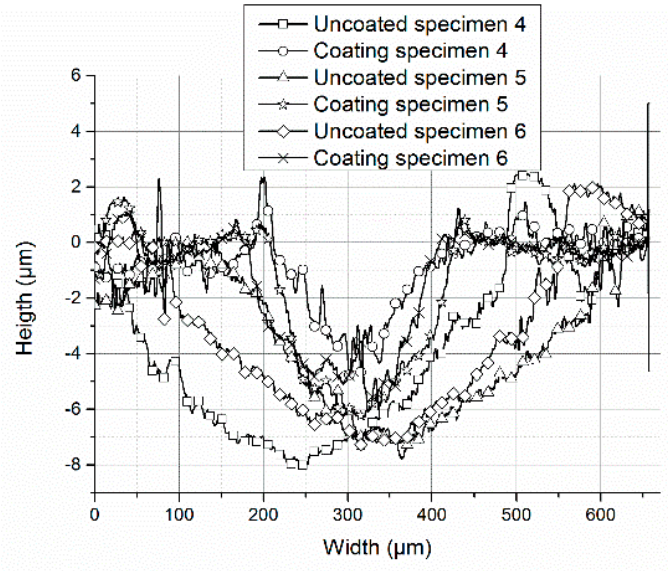

(b)

Figure 6. Cont. 


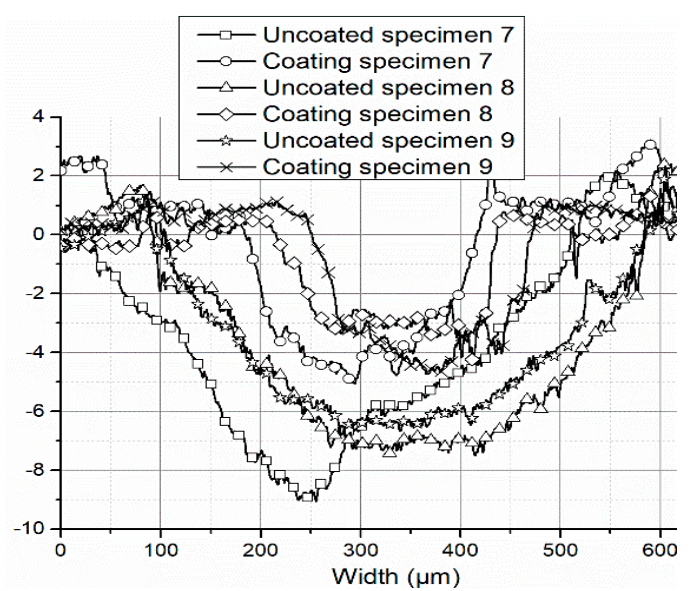

(c)

Figure 6. Curve diagram of the wear section of specimens: (a) Nos. 1-3 specimens; (b) Nos. 4-6 specimens; (c) Nos. 7-9 specimens.

Wear rates of the specimens were calculated by Equation (2), where $\omega, V, L$, and $N$ represent respectively, wear rate, wear volume, sliding distance, and load. The wear volume could be calculated from the oscillating amplitude multiplied by the curvilinear integral area of the track's profile.

$$
\omega=V /(L \times N)
$$

The wear rates of specimens are shown in Table 9. The wear resistance property of uncoated specimens was much worse than that of uncoated specimens. The wear rates of the uncoated specimens were 2-4 times that of the corresponding coating specimens respectively, which illustrates that the TiAlN/TiN coating has good wear resistance. From Table 9, it can be obtained that the wear rates of Nos. 4, 8, and 9 specimens were lower, while these three groups of specimens also had a better microhardness, adhesion, and thickness corroding to the Tables 3,4 and 6. That means that when the comprehensive property of the microhardness, adhesion, and thickness of the coating specimen was better, the abrasion resistance was also better. Different process parameters had different effects on the abrasion resistance of the coating. This is because the coating had a good protective effect on the substrate, when the adhesion is large, it is hard for the coating to fall off from the substrate, then the specimen is more wear-resisting. Taking wear rate as the target result, the range analysis of the orthogonal experiment is shown in Table 10.

Table 9. Wear areas and wear rates of specimens.

\begin{tabular}{ccccc}
\hline No. & $\begin{array}{c}\text { Uncoated SLM } \\
\text { Specimen }\left(\boldsymbol{\mu m}^{2}\right)\end{array}$ & $\begin{array}{c}\text { Coating SLM } \\
\text { Specimen }\left(\boldsymbol{\mu m}^{2}\right)\end{array}$ & $\begin{array}{c}\text { Uncoated SLM } \\
\text { Specimen }\left(\mu \mathbf{m}^{\mathbf{2}} / \mathbf{N}\right)\end{array}$ & $\begin{array}{c}\text { Coating SLM } \\
\text { Specimen }\left(\mu \mathbf{m}^{\mathbf{2}} / \mathbf{N}\right)\end{array}$ \\
\hline 1 & 3902.3 & 1206 & 390.23 & 120.6 \\
2 & 2277.5 & 1257.7 & 227.75 & 125.77 \\
3 & 2408 & 1150.3 & 240.8 & 115.03 \\
4 & 2680.4 & 486 & 268.04 & 48.6 \\
5 & 2158.1 & 975.4 & 215.81 & 97.54 \\
6 & 2272.4 & 879.2 & 227.24 & 87.92 \\
7 & 2474.7 & 1044.5 & 247.47 & 104.45 \\
8 & 2606.8 & 595 & 260.68 & 59.5 \\
9 & 2228.6 & 784.7 & 222.86 & 78.47 \\
\hline
\end{tabular}


Table 10. Range analysis of orthogonal experiment of wear rate as the target result.

\begin{tabular}{ccccc}
\hline \multirow{2}{*}{ Factor } & \multicolumn{3}{c}{ Sum of Results of One Level } & \multirow{2}{*}{ Range } \\
\cline { 2 - 4 } & $\mathbf{K} \mathbf{1}$ & $\mathbf{K} \mathbf{j}$ & $\mathbf{K} \mathbf{j}$ & \\
\hline Factor A & 361.4 & 234.06 & 242.42 & 127.34 \\
Factor B & 273.65 & 282.81 & 281.42 & 9.16 \\
Factor C & 268.02 & 252.84 & 317.02 & 64.18 \\
\hline
\end{tabular}

Notes: The sum of results of first level for corresponding factor; K2j: The sum of results of second level for corresponding factor; K3j: The sum of results of third level for corresponding factor; Factor A: Power; Factor B: Scanning speed; Factor C: Scanning space.

It can be seen from Table 10 that laser power is the main factor influencing coating wear rate, followed by scanning space, and finally, scanning speed, which is consistent with that of the adhesion and thickness of the coating. The range analysis results also show that the abrasion resistance of the SLM coating specimens obtained by the use of moderate laser power, moderate scanning space, and small scanning speed is better. From Table 10 it can be seen that the optimal combination of the orthogonal experiment was A2B1C2, that is, when the laser power was $190 \mathrm{~W}$, the scanning speed was $1000 \mathrm{~mm} / \mathrm{s}$, and the scanning space was $0.06 \mathrm{~mm}$, the abrasive resistance of the coating obtained was optimal. It can also be obtained from Table 9 that the wear rate of the No. 4 specimen was the minimum, which is consistent with the results of the range analysis of the orthogonal experiment.

\section{Discussion}

The microhardness of the TiAlN/TiN multilayer coating plating on the SLM specimen was more than $1100 \mathrm{HV}$, which is not only better than that of the SLM specimen uncoated, but also better than that of SLM specimen resulting from heat treatment in Reference [9] and that of the SLM specimen resulting from finish machining in Reference [19]. Nana Li and Ning Wang [20] found that the microhardness of 316 samples resulting from nitriding treatment was $510 \mathrm{HV}$ and that of 316 samples resulting from duplex surface mechanical attrition treatment (SMAT) [21] and nitriding treatment was $1050 \mathrm{HV}$, of which the 316L specimens were mechanical processing samples. However, the microhardness of the TiAlN/TiN multilayer coating plating on the SLM 361L specimen was better than that of Reference [21], which means the TiAlN/TiN multilayer coating has good hardness. The SLM 361L coating specimen can be applied to mechanical components with point contact occasions which need high-contact stress.

In this paper, the surface roughness of substrates is left out. Through the analysis of the obtained data, it can be known that the primary cause of the process parameter of SLM affecting the property of the TiAlN/TiN multilayer coating plating on the 361L specimen is that the internal structure of substrate with different process parameter of SLM is different. Because for the multi-arc ion plating technology the significance of ion bombardment is to cause the high-density defects of substrate, such as vacancy, clearance, and dislocation, which is easier to form the diffusion layer, and the existence of the diffusion layer enhances the interaction between the substrate and the coating. From Figure 1, with the different process parameter of SLM, the voids, cracks, and dimples exist in different substrate specimens, respectively. Some defects of substrate specimens such as dimples, vacancy, and dislocation are good for forming the diffusion layer and some are not. It was also proven in Figure $4 \mathrm{c}$ that the coating has major pin holes so its thickness is small. Therefore, the process parameter of SLM affects the property of the TiAlN/TiN multilayer coating by the porosity and the surface structure of the SLM substrate. According to Sections 3.3-3.5, it was obtained that the order of factors affecting thickness, adhesion, and wear rate properties of the TiAlN/TiN multilayer coating plating on the SLM 361L specimen was laser power, scanning space, and finally, scanning speed.

The optimal process parameter for the adhesion and thickness of the coating is that the laser power is $210 \mathrm{~W}$, the scanning speed is $1100 \mathrm{~mm} / \mathrm{s}$, and the scanning space is $0.06 \mathrm{~mm}$. The test result shows that large scanning space $(0.08 \mathrm{~mm})$ affects the fusion between channels in the SLM process, and when there is insufficient fusion between channels internal pores can appear, and thus affect the 
ability to resist deformation of the substrate and the coating is easier to bend and break when extruded. The coating adhesion and thickness decreased as a result. Therefore, using smaller scanning spacing when printing is beneficial to improve the internal organization of the SLM specimen and beneficial to improve the adhesion and thickness of the coating. This is because the laser can penetrate the molten metal powder and then the powder melts more fully and the fluidity of the molten pool is better when the laser power is large, the liquid spatter in the molten pool decreases when the scanning speed is moderate, and the scanning spacing is also moderate, which is beneficial to fuse fusion, reducing the gross defects of the sample and making the high-density defects reasonable.

\section{Conclusions}

In this paper, the influences and their mechanism of SLM process parameters (laser power, scanning speed, and scanning space) on the surface morphology and selected mechanical properties of the TiAlN/TiN multilayer coating plating on SLM 361L substrate were studied by an orthogonal experiment. From the discussions on the results above, the conclusions can be drawn as follows:

- The electron microscope images revealed that in the surface morphology of 361L substrate exists some voids, high-density dimples, and even cracks, and that the TiAlN/TiN multilayer coating plating on the SLM specimen was relatively flat, and there were some macro-particles in different sizes and pin holes dispersed on it. The surface morphology of the TiAlN/TiN multilayer coating plating on the SLM 361L specimen was affected by the different process parameters of SLM.

- The microhardness and the wear resistance of the TiAlN/TiN multilayer coating plating on the SLM specimen were better than that of the SLM specimen uncoated. The microhardness value of coating SLM 361L specimen was also better than that of the 361L specimen resulting from other existing post-processing technologies, such as heat treatment, finish machining, nitriding treatment, and duplex SMAT and nitriding treatment.

- The laser power was the main factor influencing the adhesion and the thickness of the coating, followed by scanning space, and finally, scanning speed. When the laser power was $210 \mathrm{~W}$, the scanning speed was $1100 \mathrm{~mm} / \mathrm{s}$, and the scanning space was $0.06 \mathrm{~mm}$, the adhesion and the thickness of the coating were optimal.

- The laser power was the main factor influencing the wear rate of the coating, followed by scanning space, and finally, scanning speed. When the laser power was $190 \mathrm{~W}$, the scanning speed was $1000 \mathrm{~mm} / \mathrm{s}$, and the scanning space was $0.06 \mathrm{~mm}$, the abrasive resistance of the coating obtained was optimal.

- The comprehensive analysis shows that the laser power had the greatest influence on the comprehensive property of the coating. When the laser power was $170 \mathrm{~W}$, the scanning speed was $1100 \mathrm{~mm} / \mathrm{s}$, and the scanning space was $0.08 \mathrm{~mm}$, the TiAlN/TiN multilayer coating plating on the SLM specimen had the best comprehensive property.

- The process parameter of SLM affects the property of the TiAlN/TiN multilayer coating by the porosity and the surface structure of the SLM substrate.

Author Contributions: Conceptualization, Y.L.; methodology, Y.L. and Y.W.; formal analysis, Y.L. and Y.W.; investigation, J.W.; data curation, Y.L. and Y.W.; writing-original draft preparation, Y.L. and J.W.; writing-review and editing, Y.L.; project administration, Y.L. and Y.C.; funding acquisition, Y.L. and Y.C.

Funding: This research was funded by The Tribology Science Fund of State Key Laboratory of Tribology (No. SKLTKF17B04); Natural Science Foundation of Guangdong Province (No. 2018A030310404) and National Natural Science Foundation of China (No. 51575191).

Acknowledgments: The author would like to thank Fenghua Su, who provide PVD/PECVD-600 multi-arc ion plating equipment for this paper and Yongqiang Yang, who provide a Dimetal-280 selection laser melting machine for this paper.

Conflicts of Interest: The authors declare no conflict of interest. 


\section{References}

1. Kruth, J.P.; Mercelis, P.; van Vaerenbergh, J.; Froyen, L. Binding mechanisms in selective laser sintering and selective laser melting. Rapid Prototyp. J. 2005, 11, 26-36. [CrossRef]

2. Bai, Y.; Yang, Y.; Wang, D.; Zhang, M. Influence mechanism of parameters process and mechanical properties evolution mechanism of maraging steel 300 by selective laser melting. Mater. Sci. Eng. A 2017, 703, 116-123. [CrossRef]

3. Bai, Y.; Yang, Y.; Xiao, Z.; Zhang, M.; Wang, D. Process optimization and mechanical property evolution of AlSiMg0.75 by selective laser melting. Mater. Des. 2018, 140, 257-266. [CrossRef]

4. Yadroitsev, I.; Bertrand, P.; Smurov, I. Parametric analysis of the selective laser melting process. Appl. Surf. Sci. 2007, 253, 8064-8069. [CrossRef]

5. Yadroitsev, I.; Smurov, I. Surface morphology in selective laser melting of metal powders. Phys. Procedia 2011, 12, 264-270. [CrossRef]

6. Thijs, L.; Verhaeghe, F.; Craeghs, T.; Van Humbeeck, J.; Kruth, J.P. A study of the microstructural evolution during selective laser melting of Ti-6Al-4V. Acta Mater. 2010, 58, 3303-3312. [CrossRef]

7. Ortner, S.R.; Lee, K.S.; Sherry, A.H. The Effect of a residual stress field on fracture initiation in RPV steel. Fatigue Fract. Eng. Mater. Struct. 2011, 34, 945-955. [CrossRef]

8. Löber, L.; Flache, C.; Petters, R.; Kühn, U.; Eckert, J. Comparison of different post processing technologies for SLM generated 316L steel parts. Rapid Prototyp. J. 2013, 19, 173-179. [CrossRef]

9. Kamariah, M.S.I.N.; Harun, W.S.W.; Khalil, N.Z.; Ahmad, F.; Ismail, M.H.; Sharif, S. Effect of heat treatment on mechanical properties and microstructure of selective laser melting 316L stainless steel. IOP Conf. Ser. Mater. Sci. Eng. 2017, 257, 012021. [CrossRef]

10. Mayrhofer, P.H.; Hörling, A.; Karlsson, L.; Sjölén, J.; Larsson, T.; Mitterer, C.; Hultman, L. Self-organized nanostructures in the Ti-Al-N system. Appl. Phys. Lett. 2003, 83, 2049-2051. [CrossRef]

11. Wei, Y.; Zong, X.; Wu, Z.; Tian, X.; Gong, C.; Yang, S.; Jiang, Z.; Chen, L. Effects of modulation ratio on microstructure and properties of TiN/TiAlN multilayer coatings. Surf. Coat. Technol. 2013, 229, 191-196.

12. Paldey, S.; Deevi, S.C. Single layer and multilayer wear resistant coatings of (Ti,Al)N: A review. Mater. Sci. Eng. A 2003, 342, 58-79. [CrossRef]

13. Wei, Y.Q.; Chun-Wei, L.I.; Gong, C.Z.; Tian, X.B.; Yang, S.Q. Microstructure and mechanical properties of TiN/TiAlN multilayer coatings deposited by arc ion plating with separate targets. Trans. Nonferrous Met. Soc. China 2011, 21, 1068-1073. [CrossRef]

14. Wei, Y.; Gong, C. Effects of pulsed bias duty ratio on microstructure and mechanical properties of TiN/TiAlN multilayer coatings. Appl. Surf. Sci. 2011, 257, 7881-7886. [CrossRef]

15. Vera, E.E.; Vite, M.; Lewis, R.; Gallardo, E.A.; Laguna-Camacho, J.R. A study of the wear performance of TiN, $\mathrm{CrN}$ and WC/C coatings on different steel substrates. Wear 2011, 271, 2116-2124. [CrossRef]

16. Hatem, A.; Lin, J.; Wei, R.; Torres, R.D.; Laurindo, C.; de Souza, G.B.; Soares, P. Tribocorrosion behavior of low friction TiSiCN nanocomposite coatings deposited on titanium alloy for biomedical applications. Surf. Coat. Technol. 2018, 347, 1-12. [CrossRef]

17. Gong, M.F.; Chen, J.; Deng, X.; Wu, S.H. Sliding wear behavior of TiAlN and AlCrN coatings on a unique cemented carbide substrate. Int. J. Refract. Met. Hard Mater. 2017, 69, 209-214. [CrossRef]

18. Guan, X.; Wang, Y.; Zhang, G.; Jiang, X.; Wang, L.; Xue, Q. Microstructures and properties of Zr/CrN multilayer coatings fabricated by multi-arc ion plating. Tribol. Int. 2016, 106, 78-87. [CrossRef]

19. Kaynak, Y.; Kitay, O. Porosity, surface quality, microhardness and microstructure of selective laser melted 316L stainless steel resulting from finish machining. J. Manuf. Mater. Process. 2018, 2, 36. [CrossRef]

20. Li, N.; Wang, N. The effect of duplex surface mechanical attrition and nitriding treatment on corrosion resistance of stainless steel 316L. Sci. Rep. 2018, 8, 8454. [CrossRef]

21. Tao, N.R.; Wang, Z.B.; Tong, W.P.; Sui, M.L.; Lu, J.; Lu, K. An investigation of surface nanocrystallization mechanism in Fe induced by surface mechanical attrition treatment. Acta Mater. 2002, 50, 4603-4616. [CrossRef]

(C) 2019 by the authors. Licensee MDPI, Basel, Switzerland. This article is an open access article distributed under the terms and conditions of the Creative Commons Attribution (CC BY) license (http://creativecommons.org/licenses/by/4.0/). 